\title{
Fish mislabelling in France: substitution rates and retail types
}

Julien Bénard-Capelle, Victoire Guillonneau, Claire Nouvian, Nicolas Fournier, Karine Le Loët, Agnès Dettai

Market policies have profound implications for consumers as well as for the management of resources. One of the major concerns in fish trading is species mislabelling : the commercial name used does not correspond to the product, most often because the product is in fact a cheaper or a more easily available species. Substitution rates depend heavily on species, some being often sold mislabelled while others rarely or never. Rates also vary largely depending on countries.

In this study, we analyse the first market-wide dataset collected for France, the largest sea food market in Europe, for fish species substitution.

We sequenced and analysed 371 samples bearing 55 commercial species names, collected in fishmonger shops, supermarkets and restaurants, the largest dataset assembled to date in an European country. Sampling included fish fillets, both fresh and frozen, and prepared meals.

We found a total of 14 cases of mislabelling in five species : bluefin tuna, cod, yellowfin tuna, sole and seabream, setting the overall substitution rate at 3.7\% (ci :2.2-6.4\%), one of the lowest observed for comparable surveys with large sampling. We detected no case of species mislabelling among the frozen fillets or in industrially prepared meals, and all the substitutions were observed in products sold in fishmongers shops or restaurants.

The rate of mislabelling does not differ between species, except for bluefin tuna. Despite a very small sample size $(n=6)$, the rate observed for this species (83.3\%, ci:36-99\%) stands in sharp contrast with the low substitution rate observed for the other substituted species. In agreement with studies from other countries, this work shows that fish mislabelling can vary greatly within a country depending on the species. It further suggests that more efforts should be directed to the control of high value species like bluefin tuna. 
1 Julien Bénard-Capelle ${ }^{1}$,Victoire Guillonneau ${ }^{2}$, Claire Nouvian ${ }^{2}$, Nicolas Fournier ${ }^{3}$, Karine Le 2 Loët ${ }^{4}$, Agnès Dettai ${ }^{5^{*}}$.

3 1. Institut National de la Santé et de la Recherche Medicale, Unité 1001 Robustness and

4 Evolvability of Life, Université Paris 5, Paris

5 2. BLOOM, Paris

$6 \quad{ }^{3 .}$ Oceana Europe, Brussels

7 4. Terra Eco, Nantes

$8 \quad{ }^{5 .}$ Muséum national d'Histoire naturelle, Département Systématique et Évolution, UMR 7205

9 MNHN-CNRS-UPMC-EPHE, Paris, France

$10 *$ corresponding author : adettai@mnhn.fr 


\section{Introduction}

12 Fish species represent an important and globally growing food resource. Most of the fish supply

13 is harvested in the wild, as aquaculture represents just over $42 \%$ of the fish consumed in the

14 world (FAO 2014) and only slightly more than 30\% for France (Meunier et al. 2013). An efficient management of these natural resources is particularly important, as currently $29.9 \%$ of fish stocks are overexploited, $57.4 \%$ are fully exploited, and $7.6 \%$ of global production comes from stocks that are collapsed or recovering (FAO 2012). However, the management of wild marine resources is adversely affected by unreliable traceability and labelling, impeded by the wide trade of aquatic food (Cochrane et al. 2009). A wide array of species coming from geographically distant areas is now available in many markets, making effective control along the supply chain complex.

In Europe, a number of policies regulate seafood labelling and traceability (Regulations (EC) 104/2000, 2065/2001, 178/2002, 1224/2009). Efforts have also been directed towards consumers to drive demand towards species with less conservation issues. In France as in other countries, fish buying guides are available to help customers choose among species depending on conservation issues, origin of the product, fishing methods or season (Hanner et al. 2011, Jacquet and Pauly 2008).

Mislabelled fish puts the customer at risk of unknowingly purchasing products not corresponding to their ethical or taste criteria (Rasmussen and Morrissey 2008, Jacquet and Pauly 2008). When mislabelling is discovered and made public, this may reduce trust between consumers and suppliers. Moreover, some species or provenances can even represent health hazards (Jacquet and Pauly 2008). The species designation is therefore crucial for an informed choice by consumers, and needs to be reliable and correct. In Europe, fish is second on the list of products that are the most at risk from food fraud, and Europol has observed a rise in the number of general food fraud cases (Committee on the Environment, Public Health and Food Safety, European Parliament, 2013).

The advent of molecular identification methods has given rise to a scientific attempt to quantify the amount of seafood mislabelling. While protocols and methods are not yet standardized, these studies have shown that the situation varies greatly between products and countries (Barbuto et al. 2010, Curatelli et al. 2014, Di Pinto et al. 2013, Filonzi et al. 2010, FSAI 2011, GarciaVasquez et al. 2011, Griffith et al. 2013, Huxley-Jones et al. 2011, Lowenstein et al. 2009, 
43 2009). For instance, high rates of substitution have been observed in Italy for some species

44 (77.8\% for Mustelus sp., in Barbuto et al. 2009, or 53.36\% for cod in Di Pinto et al. 2013) while

45 less than 1.5\% substitutions were uncovered in industrially prepared food purchased in British

46 supermarkets (Huxley-Jones et al. 2011). This first suggests that any attempt to quantify the rate

47 of fish mislabelling in a new country or region must be done carefully, using a wide sampling as

48 representative as possible of the market. This diversity of results also calls for a comparative

49 analysis of different markets : understanding the ecological, cultural and economic grounds

50 influencing mislabelling might help reduce it.

51 France is the largest seafood/fish market among European countries, with more than 2 millions

52 tons consumed in the country, and is ranked $7^{\text {th }}$ for per capita consumption (FAOSTAT data for

53 year 2011), yet no results have been published on fish mislabelling.

54 Government agencies regularly control the quality of the seafood supply but their conclusions are 55 not available to the public (DGCCRF 2013).

56 Food control, and the detection of species substitution in particular, has benefited greatly from the

57 development of DNA-based methods to identify species food content when morphology cannot

58 be used. These techniques provide cheap and fast identification with little need for initial

59 knowledge of the samples. They have proved very useful for the identification of fish species (for

60 a review, see Griffith et al. 2014, Rasmussen and Morrissey 2008). Among the markers used,

61 mitochondrial DNA sequences have emerged as near-universal markers for precise determination

62 of species. The most frequently used sequences are partial cytochrome b, partial $16 \mathrm{~S}$ or $12 \mathrm{~S}$

63 ribosomal DNA, and partial cytochrome oxidase I (COI). The DNA sequence is then compared to

64 reference sequences to identify the taxonomic group. The development of online databases

65 containing thousands of DNA sequences has further enhanced the reliability and ease of use of

66 these methods. It is particularly important that the reference sequence for the searched species is

67 present in the reference dataset, so more complete datasets are more valuable (Ekrem et al. 2007).

68 The Barcode of Life Database (BOLD, Ratnasingham and Hebert 2007) currently contains almost

69150,000 COI barcode sequences for almost 14,000 actinopterygian species. Cytochrome $b$, the

70 second largest, only has around 82,000 sequences listed in the GenBank nucleotide database.

71 Additional features of the Barcode of Life project, such as linking sequences to vouchered

72 specimens and specimen data, increase reliability compared to the notoriously high error rates in

73 GenBank (Harris 2003, Rasmussen and Morrissey 2008). With the success of the Barcode of Life

74 Project for fish (Ward et al. 2009) its reference marker, COI, has been increasingly used for 
75 identifications and represents the majority of substitution studies in the last years. Other datasets

76 for the regulatory identification of species substitutions have also been established for COI, for

77 instance in the Regulatory Fish Encyclopedia of the Food and Drug Administration (Yancy et al. 78 2008).

79 The present study, the first of its kind for France, therefore aims to evaluate the extent of

80 mismatch between the market names and the actual species for some of the most common

81 commercial marine fish species in France including Bar, Lieu noir, Cabillaud, Merlu, Lotte,

82 Merlan, Sole, Pangas, Raie Thon and other less represented species. The difference between

83 results by country and species hints at different and specific effects depending on the market. A

84 study widely sampling the diversity of fish products available to the customer in France was

85 therefore required for a first assessment of substitution rates. We focussed on the less

86 recognizable products: fillets (both sold by fishmongers and industrially packaged or deep-

87 frozen), and dishes (either ready-made or served in restaurants). These products are particularly

88 susceptible to be substituted as the customers and control agencies cannot easily recognize the

89 species from the appearance of the product. Two collecting efforts have been started in parallel by

90 the NGO Oceana, associated with the magazine Terra Eco, and the NGO Bloom, in collaboration

91 with researchers from the French National Institute of Health and Medical Research (INSERM)

92 and National Museum of Natural History (MNHN). These two initiatives took advantage of the

93 development of citizen science to increase the sampling's coverage, both geographically and by

94 place of purchase. They are both analysed and presented in this article, resulting in the largest

95 European dataset for such a study.

\section{Material and methods}

\section{Sampling}

98 Samples and corresponding data were collected across continental France between April and

99 December 2013. Two independent sets of samples were collected, hereafter referred to as

100 FishLabel (FL) and TerraEco (TE).

101 FishLabel set

102 The FL set was collected in pre-numbered tubes and stored until extraction in 95\% ethanol. Each

103 sample was divided at sampling in two tubes with the same sampling number. Commercial name,

104 Latin name when indicated, date, collector, location, brand name, shop or restaurant names were

105 collected, as well as photographs of packages and samples when possible. The data were 
106 collected either on paper forms sent along with the samples or uploaded online using the

107 smartphone application Epicollect (Aanensen et al. 2010). Only fillets or fish dishes were

108 sampled, as they are not readily identifiable and thus potentially easier to substitute. They were

109 collected from fishmonger shops, restaurants, and supermarkets (either at the fishmonger

110 department or industrially prepared, i.e. canned or fresh ready-made meals and deep-frozen

111 fillets). To avoid dispersion over a large number of species, we focused the sampling on ten

112 commercial names chosen among the most consumed fish species in France (according to

113 www.franceagrimer.fr, checked April 2013): Bar or Loup, Lieu noir, Cabillaud, Merlu or Colin,

114 Baudroie or Lotte, Merlan, Sole, Pangas, Raie, Thon (See table 1 for correspondance with species

115 names and English names). Although salmon is the most consumed fish in France, we initially

116 excluded all salmon species from the list of targeted species because the market is dominated by

117 cheap Salmo salar from aquaculture, which is expected to be less substituted because of its price.

118 The detailed instructions to the samplers are provided online (in French and translated in English,

119 FigShare http://dx.doi.org/10.6084/m9.figshare.978485). The collectors were contacted through

120 the personal connections of the authors. They were provided with sampling kits containing ten

121 collecting tubes and written detailed instructions, as well as a return envelope.

122 Terra Eco set

123 Detailed instructions to the samplers are provided online (in French and translated in English,

124 FigShare http://dx.doi.org/10.6084/m9.figshare.978485), following the protocol used by Oceana

125 in the USA. The collectors were asked to sample only the products labelled as Cabillaud (cod),

126 Lotte (anglerfish) or Thon rouge (bluefin tuna). Only one tube was prepared for each sample, and

127 they were conserved in silica gel until extraction.

1D8/A extraction and sequencing

129 Prior to analysis, the samples that lacked crucial data (defined as collection site, retail name, dish

130 name including species name and collector, and clear indication of the sample number) were

131 excluded. The FL samples were extracted using an epMotion 5070 (Eppendorf) and Tissue

132 extraction kits (Macherey Nagel) following the instructions from the manufacturer. For practical

133 reasons, samples that arrived later were extracted following the protocol in Winnepenninckx et al.

134 (1993).

135 The partial COI was amplified using the primers FishF1, FishF2 and FishR1 from Ward et al.

136 (2009) and TelF1 and TelR1 from Dettai et al. (2011). Samples with denatured DNA could not be

137 successfully amplified, and the published primers for short fragments amplified regions gave no 
138 variability between most Thunnus species. New primers were therefore designed flanking

139 variable areas and diagnostic sites of the Thunnus sequences (Lowenstein et al. 2009): COIF268-

140 5' GAAACTGACTYATTCCTYTAATGAT 3', COIF270-5'

141 AACTGACTTATTCCYYTAATGATYGG 3', COIR450-5'

142 GAAGTTAATTGCCCCAAGAATTGA 3', and COIR445-5'

143 AAGTTAATTGCTCCAAGAATTGAWGA 3'. Combinations of FishF1 or TelF1 and FishR1 or

144 TelR1 produced a fragment of $652 \mathrm{bp}$, the primer couples COIF268-FishR1 or COIF268-TelR1

145 produced intermediate-sized fragment of $442 \mathrm{bp}$, and COIF268-COIR450 produced $208 \mathrm{bp}$

146 fragments. All samples were first tested with the primers for the longest fragment. If this PCR

147 was unsuccessful, we tested the intermediate size, and finally the shortest fragment. PCR

148 followed Dettai et al. (2011) on Biorad thermocyclers. Purification and sequencing of the PCR

149 products were performed commercially by GATC (http://www.gatc-biotech.com/) using the same

150 primers. Most sequences were obtained in only one direction, but as a precaution, 70 samples

151 chosen at random were sequenced in both directions. Samples where molecular identification

152 differed from the commercial label were extracted from the second sample tube using the

153 protocol in Winnepenninckx et al. (1993), amplified and sequenced a second time, when possible

154 with a different pair of primers. Sequences were checked manually against their chromatogram

155 using Codoncode Aligner (CodonCode Corporation) and then exported and aligned in Bioedit

156 (Hall, 1999).

157 The TE samples were extracted, amplified and sequenced with the same primers by Spygen, a

158 commercial company specialised in molecular identification (http://www.spygen.fr/). The

159 sequences provided were analysed by the same person, and using the same approaches as the FL

160 dataset.

161 Sample descriptions and sequences are available in the Barcode of Life Database in the FSCF

162 project (FCSF001-14 to FCSF291-14 for the FL dataset, FCSF292-14 to FCSF404-14 for the TE

163 dataset), and in GenBank. Collector names, brands and precise collection data were anonymized.

164 Photographs are included for samples when they do not threaten the anonymity of the data.

\section{5 lecular identification}

166 Three datasets were assembled according to the length of the sequences obtained (long,

167 intermediate or short sized fragments). Within each dataset, pairwise distance trees were built

168 with the taxon ID tree function included in BOLD to cluster identical sequences. These sequences

169 were grouped in the alignment files, and sequence identities were also checked on the alignments. 
170 Each distinct sequence was then used to BLAST-search the Barcode of Life database. The long

171 dataset was compared to the Species Level Barcode Records while the medium and short datasets

172 were matched to the Full Length Record Barcode Database to avoid issues due to insufficient

173 overlap of the sequences with the reference dataset. Identification was determined by sequence

174 similarity to the reference dataset (Wong and Hanner 2008), and checked through their position

175 (Costa et al. 2012) in the "Tree based identification" generated distance trees in BOLD. For

176 species with low interspecific divergences (Gadus and Thunnus species), aligned sequences

177 were compared to each other, to sequences from the BOLD, and to sequences from the FDA

178 reference dataset for Seafood identification

179 (http://www.fda.gov/Food/FoodScienceResearch/DNASeafoodIdentification/ucm238880.htm).

180 Additionally, we checked species-specific characteristic attributes and characteristic

181 combinations on the alignments following Lowenstein et al. (2009).

18Rslabelling determination

183 For each sample, the list of admissible species that can be sold under the commercial name

184 indicated on the menu, the price tag, or the box was determined by consulting a governmental

185 website (http://www.economie.gouv.fr/dgccrf/Poissons, last checked on 25/02/2014). The sample

186 was declared mislabelled if the species name determined through molecular identification was

187 not in this list.

188 We did not retain the commercial names obtained orally from the waiting staff in the calculations

189 of the substitution rates. However, we have kept this information in the data files.

\section{0ouping of commercial names}

191 The total number of commercial denominations retrieved from the completed forms was high (55

192 different commercial names), preventing statistical analysis of a large part of the dataset. The

193 samples were thus grouped into broader commercial categories. For instance « cabillaud» (cod)

194 was grouped with « cabillaud du pacifique » (pacific cod) and « morue » (a French nomenclature

195 for dry and salted cod, whether Pacific or Atlantic) under « cabillaud». This and similar cases

196 reduced the number of categories to 30 . We further decreased the number of categories by

197 keeping only those for which at least 10 samples were available. All the other samples were

198 grouped under the « other » category. However, after a preliminary analysis it appeared that the

199 mislabelling signal detected for the «tuna» category was mostly attributable to the samples sold

200 as «bluefin tuna». To account for this fact, this category was then split into « bluefin tuna » and

201 « tuna », although only 6 samples fall under the « bluefin tuna » name. This procedure ensures 
202 that most categories have a large enough sample size for statistical analysis while being

203 representative of the French market.

204 Note that for reading convenience and international comparison, the French fish names have been

205 translated into their English equivalent when available and used throughout this study (table 1).

206 Some could not be translated, like « colin » referring to a broad category of white meat species,

207 and were kept in their original form. Furthermore, as the French vernacular names relate to the

208 local naming traditions, they might not designate the same species as in countries using the

209 English equivalent. For instance "albacore" refers in French to Thunnus albacares, while in

210 English it refers to Thunnus alalunga.

\section{Stretistical analysis}

212 The substitution status of the samples was analysed as a binary variable using a generalized linear

213 model with a binomial error distribution and a logit link function. The type of protocol, retail

214 type, species category and type of product sold were included as explanatory variables, with

215 interactions.

216 After removal of the non-significant interactions and variables, Tukey Honest Significant

217 Differences were calculated from the final model.

218 The influence of the price was investigated in a separate analysis for a subset of 156 samples for

219 which the information on the price was available and could be expressed in $€ / \mathrm{kg}$. The

220 substitutions were modelled as above with the price, the retail conditions and the type of shop as

221 independent variables, with interactions.

222 All the confidence intervals $(\alpha=0.05)$ were calculated using Wilson's method. The statistical

223 analysis was performed with R (R Core Team, 2013) and both the script used and the original

224 data file are available on the figshare repository (http://dx.doi.org/10.6084/m9.figshare.978485).

\section{8stpplier interviews}

226 A follow-up investigation was performed for samples for which mislabelling was detected.

227 Retailers were met in person or contacted over the phone. Interviews started by presenting the

228 study, the sample purchased in the shop and explaining that we detected a mismatch between the

229 molecular determination and the label. Then the supplier was asked several questions (figure S1)

230 to determine whether the substitution was intentional and if so, what motivated it. 


\section{Results}

\section{SRmpling and sequencing}

233 We collected 291 samples using the FL protocol, out of which 276 could be sequenced. We

234 obtained 172 long sequences, 97 intermediate length and seven short sequences. Fifteen samples

235 (5,16\%) could not be amplified at all, a failure rate comparable to other studies of this type

236 (Hanner et al. 2011, Cawthorn et al. 2012). These included nine ready-made dishes, the single

237 canned sample present in the sampling, two smoked fillets, and three restaurant dishes, all

238 sources that are expected to show some DNA degradation.

239 All 114 TE samples provided sequences (45 long sequences and 69 short).

240 Both datasets together added up to 390 sequences. Nineteen of these were then removed because

241 important information was missing, or doubts remained on the quality of the collected data. The

242 final dataset therefore included 371 samples.

\section{WBlecular identification}

244 Identifications using the sequence similarity, the position in the BOLD distance trees and the

245 verification of species-specific sites in the sequences gave congruent results. For $90 \%$ of the

246 samples the similarity with sequences present in BOLD was high, between $99.19 \%$ and $100 \%$.

247 Almost all species included in the study were represented in the BOLD by barcode clusters that

248 are single, cohesive, and non overlapping with other species clusters (Hanner et al. 2008), a

249 prerequisite for good identification. Most groups also had relatively high interspecific

250 divergences in BOLD even with the most closely related species, making assignation to a single

251 species straightforward. Tree-based identifications placed most samples within large clusters of

252 samples with the same identification (grade A identification according to Costa et al. 2012). All

253 these can therefore be considered as non-ambiguous, high reliability identifications. It was

254 however less straightforward for three groups (European sea bass, tuna and rockfish), although

255 the end result can be considered reliable.

256 First, "bar" (European sea bass, Dicentrarchus labrax) is represented by three divergent clusters

257 in BOLD. Part of our samples are almost identical to samples from the UK and Spain, the rest to

258 samples from Turkey and Portugal. These two groups of sequences diverge by $2,5-3 \%$ from each

259 other. Therefore, D. labrax samples had a grade C identification (Costa et al. 2012) if considering

260 only the sequences in BOLD. However, one of these groups of sequences is identical (or with one

261 base divergence) with the highly reliable FDA208 Dicentrarchus labrax sequence in the 
262 Reference Standard Sequence Library for Seafood Identification of the FDA, and the reliability

263 of the identification for the second group is also supported by reference sequences from

264 independent datasets in BOLD.

265 Conversely, tuna species presented little interspecific divergence and are difficult to identify

266 using similarity or clustering-based methods (Lowenstein et al. 2009, Vinas and Tuleda 2009).

267 However some species had clear shared sites in the sequences (Lowenstein et al. 2009) that could

268 be used to group the sequences. This was the case for Thunnus thynnus ("thon rouge"), Thunnus

269 alalunga, and our samples of Thunnus obesus. Thunnus albacares sequences in BOLD formed a

270 cluster with more variability. This cluster also contains sequences identified as other Thunnus

271 species. As these other species usually group in distinct BOLD clusters, the most probable

272 explanation of their placement in the T. albacares cluster is misidentification of some of the

273 sequences in BOLD. Therefore sequences falling into this cluster were attributed to T. albacares.

274 Third, the "sebaste" (rockfish) sample was embedded within a cluster of related rockfish

275 sequences from BOLD. This cluster also contained sequences from other closely related species.

276 Therefore, only genus-level identification was possible. The same problem had already been

277 encountered by Wong and Hanner (2008) and Hanner et al. (2011) on the same genus.

278 Two pairs of mixed samples could be identified (FL0084 and FL0085, FL1263 and FL1266).

279 Each sample of the pair originate from the same collection event (same day, same place, same

280 collector) and the molecular identifications are exactly switched. As the most probable

281 explanation is accidental exchange by the collector, these samples were switched back and kept

282 for analysis.

283 The summary of the commercial names and species determination is presented in table 1. A total

284 of 42 species were identified. This number far exceeds the number of targeted species because i)

285 several species can be sold under a given commercial name, ii) the substitutions increase the

286 number of species detected and iii) the collectors sampled more species than targeted.

\section{7pecies substitution}

288 Among the 371 samples analysed, we found 14 cases of species substitution representing a rate of

$2893.7 \%$ (ci 2.2-6.4\%, table 2). We found substitutions for the following five fish species: bluefin

290 and yellofin tuna, cod, sole and red porgy/seabream (see table 2). As expected, most of these

291 products were substituted for species with a lower market value. Five substitution cases were

292 observed for bluefin tuna, although this species is represented by only 6 samples. The substitution

293 rate for this species is $83 \%$ with a confidence interval of $36-99 \%$. 
294 The species representation was largely uneven with the top five species totalling $67 \%$ of the 295 samples and none of the remaining categories containing more than 18 samples (figure S2). The

296 samples were more evenly distributed among retail types with 74 samples from fishmongers, 100

297 from restaurants and 197 from supermarkets.

298 No effect of the protocol (FL or TE) on the rate of substitution was detected in the full model.

299 They were thus pooled. The « species » variable has an impact on the rate of mislabelling

300 ( $<<0.001$, figure 1). Post-hoc testing indicates that this is due to the «bluefin tuna » category

301 being significantly different from the three categories with the largest number of samples, i.e.

302 « $\operatorname{cod} »$, « other » and « tuna » (respectively $p=0.004, p=0.006, p=0.012$ ).

303 The different modes of retail also show a marginally significant difference among them

304 ( $p=0.085)$, as species substitution was found only for products sold as fresh fillets or as

305 restaurants meals (figure S3).

306 No effect of the price on the probability of species substitution was observed (data not shown).

30articipative collection

308 The whole TE sampling and part of the FL sampling were done by volunteers. The sampling

309 effort is very broadly distributed with the top 3 collectors contributing to $36 \%$ of the sampling

310 efforts (with respectively 72,49 and 15 samples), while $75 \%$ of the collectors contributed one or

311 two samples each.

3slppplier interviews

313 Out of the 14 cases of mislabelling identified, four fish retailers, two restaurant owners and four

314 supermarket executives were contacted in person or over the phone. In five cases, they responded

315 positively up to the third question, acknowledging an intentional substitution. Two non-exclusive

316 reasons were given: i) increased gains due to the price difference between the two species and ii)

317 replacement of a highly demanded species by an easily available, less considered species.

\section{Discussion}

319 This study is the first assessment of fish mislabelling in France, the largest seafood market among

320 European countries. The samples presented observed an overall rate of substitution of $3.7 \%$ (ci

321 2.2-6.4\%), which is low compared to the rates reported for most other countries (table 3). This

322 rate might partly be a consequence of our broad sampling scheme including multiple sample

323 sources and supply lines. Contrary to fresh fillets or restaurants meals, both known to be prone to

324 species substitution, industrial products like deep-frozen fillets or ready-made meals have been 
325 shown to present either very low substitution rates, like in the UK (below 1.5\% for fish fingers,

326 Huxley-Jones et al. 2012) or much higher ones (above 30\%, Di Pinto et al. 2013, Garcia-Vasquez

327 et al. 2011), depending on the country. We found no case of substitution among these products in

328 our sampling, suggesting that the situation in France is closer to that of the UK. The low rate

329 observed for these products might thus have decreased the overall substitution rate in our study.

330 The difference in substitution rates between countries might be the result of many social and

331 economic factors, such as the rate of control by government agencies or the length of the supply

332 chain, but few of them have been specifically investigated. One notable exception is the case of

333 Ireland, where media attention led to an improvement in substitution rates (Mariani et al. 2014).

334 However, due to the lack of older data for France, it is not possible to know whether there was a

335 similar effect and if the rates have changed over time.

336 Fish species substitution rates have also proved to be highly variable among European countries

337 (table 3). However, the sample acquisition method is not standardized across studies and

338 comparisons between the observed rates must be undertaken with care. Notably, species

339 availability, prices and consumers preferences differ between geographic areas and limit

340 comparisons across studies and countries. Cod is probably the species that can best be compared,

341 as it is represented in most studies by the largest number of samples. Our cod sampling is similar

342 in size to the sampling of several cod-centered publications (Di Pinto et al. 2013, Miller and

343 Mariani 2010, Miller et al. 2012). In comparison, our substitution rate is one order of magnitude

344 lower than in Italy (Di Pinto et al. 2013) or Ireland (Miller and Mariani 2010, Miller et al. 2012,

345 table 3), and similar to the UK (7.4\% in Miller et al. 2012). This low rate for France is very

346 encouraging, but the origins of the differences between countries remain to be investigated. They

347 might provide clues for a better resource and market management.

348 While the substitution rate is low, there is a consistent pattern : a species is replaced by one with a

349 lower commercial value. This pattern is also observed in other countries and is hinting at

350 economic motives. We did not observe substitutions of species claimed to be sustainable by

351 species that are not, whereas in the UK Pacific cod replaces Atlantic cod (Miller et al. 2012). Our

352 dataset contains very few samples of the Pacific species Gadus macrocephalus, although it is

353 legally acceptable under the widely-used commercial name "cabillaud".

354 Since the number of samples per species shows high variability (fig S1) and the substitution rate

355 is low, we observed few cases of mislabelling per fish name category, preventing detailed

356 comparisons between them. However, we detected an effect of the "commercial name" variable 
on the substitution rate. This effect was mostly due to bluefin tuna. Market issues are particularly

358 important for bluefin tuna because of its conservation status. Strikingly, we found this species to

359 be highly mislabelled with 5 out of 6 samples being substituted (i.e. $83 \%$, ci : 36-99\%), which

360 stands in sharp contrast with the low substitution rate over the whole sampling. Contrary to some

361 other studies (Wong and Hanner 2008 for instance), however, bluefin tuna was substituted with

362 other tuna species, and never with unrelated species. Moreover, for 16 samples collected in sushi

363 restaurants the waiters replied upon enquiry that the tuna sold was bluefin tuna, which was never

364 the case (data not shown but included in the BOLD repository). Although we excluded these

365 samples from our analysis because the menu was not precise enough, this shows an absence of

366 care or knowledge in the usage of this commercial name.

367 The catches of this species are largely debated and presented in the media, with positive effects

368 on fisheries management (Fromentin et al. 2014). They probably make up the most lucrative

369 fisheries in the world, driven by strong demand from the Japanese market ( $80 \%$ of the global

370 catches) (European Commission PR 2009). This commercial importance led to severe overfishing

371 during the 1990-2000s, with estimates of stock declines of 72\% in the Eastern Atlantic, and of

$37282 \%$ in the Western Atlantic (ICCAT, 2009). International concerns over the species survival

373 culminated in 2009 with the proposal to protect bluefin tuna under the UN Convention on

374 International Trade in Endangered Species (CITES, 2008), which was eventually rejected. Since

375 then, the implementation of strengthened management measures resulted in reductions in catches

376 and fishing mortality rates, indicating that the species may be slowly recovering (Fromentin,

3772008 ; ICCAT 2013).

378 There are at least two plausible explanations for the high mislabelling rate of this species. First,

379 bluefin tuna is called « red tuna » («thon rouge ») in French. This might confuse waiters and

380 customers, as fresh tuna meat is reddish. Therefore, any raw tuna meat can appear as

381 « red ».Second, as highlighted by its conservation issues, this species is considered on the French

382 and other markets to have a high quality meat and might appear more attractive to the customers.

383 These two factors might have acted together, the high demand of customers pushing the retailers

384 to take advantage of the confusing French name of the species.

385 The probability of substitution might also be influenced by the retail type, although this trend is

386 not statistically significant in our study. This might be due to the small number of substitutions

387 observed $(\mathrm{n}=14)$, but several lines of evidence suggest that there might be a real difference. First,

388 we found no case of substitution in industrially processed food like prepared meals $(n=67)$ or 
deep-frozen fillets ( $n=33$, figure S3). For a species heavily used by the industry like the Alaska pollock, we observed no case of substitution despite a significant sample size ( $\mathrm{n}=33$ ). Second, 10 out the 14 substitutions were investigated by interviews with suppliers. In five cases out of ten, the people responsible for the last step before the fish reaches the consumer admitted intentional substitution for increased profit or consumer expectation reasons, in agreement with studies in other countries (as reviewed in Jacquet and Pauly 2008). There are no such last steps for the prepared meals and deep-frozen fillets.

Our study was made possible by the involvement of dozens of volunteers throughout France. Citizen science has emerged in the last decades as a way for scientists to have access to large datasets extending the studies in space and time (Hochachka et al., 2012) or to have humans performing tasks that computers can not, as exemplified by the Galaxy Zoo (Clery, 2011) or FoldIt (Cooper et al. 2010) projects. Some authors have distinguished different types of collaborative work between scientists and citizen, depending on the involvement of citizens in the research tasks (Cooper et al. 2007). Our study has a mixed type of research management. It was initiated by non-scientists involved in controlling the economic use of natural marine resources. They were then joined by scientists to ensure that the study will meet the stringent criteria of peer-reviewed science, a model refered to as « participatory action research » by Cooper et al. (2007). Finally, volunteers were recruited to enlarge the dataset, following a research model more common in citizen science. So our study has mobilized two types of citizens : the initiators of the study, who actively participated in all the research tasks, and the collectors, who enabled the large scale of the study by collecting samples.

Involvement of non-specialists can represent a problem for the reliability of the sampling. For instance, if there were mistakes by inexperienced collectors, the most probable effect is additional "substitutions" recorded (false positives), with our results being an over-evaluation of the real number. It was not possible to check the whole sampling process for each collector, but we checked the samples of each collector to know whether they sampled more substituted products than average. We also carefully checked each substitution case. All of them came from different retailers, except for one supermarket line for which two substitutions were detected from two different species by two different samplers in two different areas of the country.

However the very low substitution rates found in this study also confines the potential problem. If over-enthusiastic collectors focussed on places where they expect to find substitutions, or made mistakes in the collecting, they might have increased the number of substitutions compared to a 
421 non-biased sampling. While we cannot exclude such a bias, it would mean that the rate of

422 substitutions is actually even lower than described here. However, at least 5 of the 14 cases were

423 corroborated by the persons responsible for the substitution themselves. They form therefore a

424 reliable minimum, with a maximum at 14 (still very low compared to most other studies already

425 published, see table 3), as all our possible biases would tend to increase the number of

426 substitutions recorded.

427 The congruent results for the two sets (TE and FL) collected and sequenced independently also

428 speaks in favour of the reliability of the sampling.

\section{Conclusion}

430 This study was designed to cover a large part of the French fish products market, as we aimed at 431 estimating mislabelling rate over multiple product types. Compared to substitution studies in 432 other countries, we observed a low substitution rate. Detailed analysis reveals two trends that 433 need further investigation.

434 First, some species appear to be more often substituted than others, with multiple cases observed 435 for cod and bluefin tuna, as was also established in other countries and studies. The substitution 436 rate on bluefin tuna was especially high,which might be linked to the the public debate on this 437 species. Specific studies focused on this species would be needed to confirm this finding in 438 France and in other countries.

439 Second, the rate of mislabelling seems to differ between supply chains. We detected no 440 mislabelling in industrial products, while several restaurant owners or fishmongers acknowledged 441 intentional substitution. This suggests that substitution is more important at the end of the supply 442 chain and that control efforts must be directed at this level.

443 Despite limitations in a few taxa, DNA barcoding based on the COI sequence provided fast, 444 efficient and unambiguous identifications for most of our commercial fish samples even when 445 only a short fragment was used, in line with previous studies (Meusnier et al. 2008). The BOLD 446 hosted dataset gave a resolution superior to the one in GenBank, and the tools available with the 447 database permit an easier evaluation of dataset quality and homogeneity.

448 Although the substitutions appear infrequent compared to other studies and concentrated on some 449 species and retail types, improvement can be made to increase the reliability of the market. In 450 particular, the scientific names were indicated for only a low proportion of the samples at sale. In 451 France like in other countries, legislation on labelling differs between restaurants, fresh sales and 
452 deep-frozen fish. For some groups like rays or tuna, the authorized commercial names cover a

453 large number of species, including species with serious conservation concerns. In such cases,

454 there is no way for knowledgeable consumers to choose according to sustainability criteria, and 455 controls could be improved without systematically resorting to testing. We join Miller et al.

456 (2012) and Jacquet et Pauly (2008) in their call for more precise and informative labelling and

457 hope that publicly available data will help citizens, through media attention, to push for this type

458 of changes as exemplified by recent progress in Ireland (Mariani et al. 2014). 


\section{Acknowledgements}

460 We thank all our collectors for their great and thorough work, and Baptiste Carton and Alexia

461 Velasquez for help with the lab work and the sequence management. Laboratory access and

462 assistance was provided by the "Service de Systematique Moleculaire" of the Muséum National

463 d'Histoire Naturelle (CNRS UMS2700 OMSI). We thank Dusan Misevic for commenting on

464 earlier versions of this paper, and S. Von der Heyden, an anonymous reviewer, and the editor R.

465 Toonen for their constructive criticisms. We also thank G. Lancelot and N. Schnell for their

466 English and content corrections. 


\section{References}

468 Aanensen DM, Huntley DM, Feil EJ, al-Own F, Spratt BG. 2009. EpiCollect: Linking

469 Smartphones to Web Applications for Epidemiology, Ecology and Community Data Collection.

470 PLoS ONE 4(9): e6968. doi:10.1371/journal.pone.0006968

471 Barbuto M, Galimberti A, Ferri E, Labra M, Malandra R, Galli P, Casiraghi M .2010. DNA

472 barcoding reveals fraudulent substitutions in shark seafood products: The Italian case of

473 “palombo” (Mustelus spp.). Food Research International 43: 376-38.

474 Cawthorn D-M, Steinman H A, Witthuhn R C .2012. DNA barcoding reveals a high incidence of

475 fish species misrepresentation and substitution on the South African market. Food Research

476 International 46: 30-40.

477 CITES. 2008. Proposal to include Atlantic Bluefin Tuna (Thunnus thynnus (Linnaeus, 1758)) on

478 Appendix I of CITES in accordance with Article II 1 of the Convention.

479 http://www.cites.org/eng/cop/15/prop/E-15-Prop-19.pdf

480 Clery D. 2011 Galaxy Zoo volunteers share pain and glory of research. Science 33:173.

481 Cline, E. 2012. Marketplace substitution of Atlantic salmon for Pacific salmon in Washington

482 State detected by DNA barcoding. Food Research International 45 388-393.

483 Cochrane K; De Young C; Soto D; Bahri T (eds). 2009. Physical and ecological impacts of 484 climate change relevant to marine and inland capture fisheries and aquaculture. In: Climate 485 change implications for fisheries and aquaculture: overview of current scientific knowledge. 486 Cochrane K; De Young C; Soto D; Bahri T (eds). FAO Fisheries and Aquaculture Technical 487 Paper. No. 530. Rome, FAO. 2009. 212p.

488 http://www.fao.org/fileadmin/user_upload/newsroom/docs/FTP530.pdf

489 Committee on the Environment, Public Health and Food Safety, European Parliament, 2013.

490 Draft Report on the food crisis, fraud in the food chain and the control thereof. De Lange, E.

491 (Rapporteur). PR\1005774EN.doc. http://www.europarl.europa.eu/sides/getDoc.do?

492 pubRef=-//EP//NONSGML+COMPARL+PE-519.759+02+DOC+PDF+V0//EN\&language=EN

493 Cooper CB, Dickinson J, Phillips T, and Bonney R. 2007. Citizen Science as a Tool for

494 Conservation in Residential Ecosystems. Ecology and Society 12:11.

495 Cooper S, Khatib F, Treuille A, Barbero J, Lee J, Beenen L, Leaver-Fay A, Baker D, Popovi Z

$496>57,000$ Foldit players. 2010. Predicting protein structures with a multiplayer online game.

497 Nature 466:756. 
498 Costa FO, Landi M, Martins R, Costa MH, Costa ME, Carneiro M, Alves MJ, Steinke D,

499 Carvalho GR. 2012. A ranking system for reference libraries of DNA barcodes: application to

500 marine fish species from Portugal. PLoS One 2012;7(4):e35858. doi:

501 10.1371/journal.pone.0035858.

502 Cutarelli A, Amoroso MG, De Roma A, Girardi S, Galiero G, Guarino A, Corrado F .2014. Italian

503 market fish species identification and commercial frauds revealing by DNA sequencing. Food

504 Control 37:46-50.

505 Dettai A., Lautredou A-C, Bonillo C., Goimbault E., Busson F., Causse R., Couloux A.,Cruaud

506 C., Duhamel G., Denys G., Hautecoeur M., Iglesias S., Koubbi P., Lecointre G., Moteki M.,

507 Pruvost P., Tercerie S., Ozouf C. 2011. The actinopterygian diversity of the CEAMARC cruises:

508 Barcoding andmolecular taxonomy as a multi-level tool for new findings. Deep-Sea Research II

509 58: 250-263.

510 DGCCRF. 2013. Résultats 2013 de la DGCCRF.

511 http://www.economie.gouv.fr/files/files/directions_services/dgccrf/dgccrf/rapports_activite/2013/

512 DGCCRF resultats2013.pdf. Last checked 26/11/2014

513 Di Pinto A, Di Pinto P, Terio V, Bozzo G, Bonerba E, Ceci E, Tantillo G. 2013. DNA barcoding

514 for detecting market substitution in salted cod fillets and battered cod chunks. Food Chemistry

515 141: 1757-1762.

516 Ekrem T, Willassen E, Stur E. 2007. A comprehensive DNA sequence library is essential for

517 identification with DNA barcodes. Molecular Phylogenetic and Evolution 43, 530-542.

518 European Commission PR. 2009. IP/09/1294 http://europa.eu/rapid/press-release_IP-09-

519 1294_en.htm?locale=en

520 FAO 2012. Situation Mondiale des Pêches et de l'Aquaculture.

521 http://www.fao.org/docrep/016/i2727f/i2727f.pdf. Last accessed 11-11-2014

522 FAO 2014. Fishery and Aquaculture Statistics 2012. http://www.fao.org/3/a-i3740t.pdf. Last

523 accessed 11-11-2014

524 FAOSTAT data accessible at http://faostat.fao.org

525 Filonzi L, Chiesa S, Vaghi M, Nonnis Marzano F. 2010. Molecular barcoding reveals

526 mislabelling of commercial fish products in Italy. Food Research International 43 :1383-1388.

527 FSAI (Food Safety Authority of Ireland). 2011. Fish Labelling Survey.

528 http://www.fsai.ie/resources_publications.html. Last accessed 28-03-2014. 
529 Fromentin JM, Bonhommeau S, Arrizabalaga H, Kell LT. 2014. The spectre of uncertainty in

530 management of exploited fish stocks: The illustrative case of Atlantic bluefin tuna, Mar. Policy.

531 47: 8-14 http://dx.doi.org/10.1016/j.marpol.2014.01.018.

532 Garcia-Vazquez E, Perez J, Martinez JL, Pardinas AF, Lopez B, Karaiskou N, Casa MF,

533 Machado-Schiaffino G, Triantafyllidis A. 2011. High Level of Mislabeling in Spanish and Greek

534 Hake Markets Suggests the Fraudulent Introduction of African Species. J. Agric. Food Chem. 59:

535 475-480. DOI:10.1021/jf103754r

536 Griffiths AM, Sotelo CG, Mendes R, Perez Martin RI, Schröder U, Shorten M, Silva HA, Verrez-

537 Bagnis V, Mariani S. 2014. Current methods for seafood authenticity testing in Europe: Is there a

538 need for harmonisation?. Food Control 45: 95-100.

539 Griffiths AM, Miller DD, Egan A, Fox J, Greenfield A, Mariani S . 2013. DNA barcoding unveils

540 skate (Chondrichthyes: Rajidae) species diversity in 'ray' products sold across Ireland and the

541 UK. PeerJ 1:e129; DOI 10.7717/peerj.129

542 Hall, T.A. 1999. BioEdit: a user-friendly biological sequence alignment editor and analysis

543 program for Windows 95/98/NT. Nucleic Acid Symposium Series No.41:95-98

544 Hanner RH, Becker S, Ivanova NV, Steinke D . 2011. FISH-BOL and seafood identification:

545 Geographically dispersed case studies reveal systemic market substitution across Canada.

546 Mitochondrial DNA, 22(S1): 106-122

547 Harris DJ. 2003. Can you bank on GenBank? Trends in Ecology and Evolution 18, 317-319.

548 Hochachka WM, Fink D, Hutchinson RA, Sheldon D, Wong W and Kelling S. 2012. Data-

549 intensive science applied to broad-scale citizen science. Trends in Ecology and Evolution 27:130

550 Huxley-Jones E, Shaw JLA, Fletcher C, Parnell J, Watts PC. 2012. Use of DNA Barcoding to

551 Reveal Species Composition of Convenience Seafood. Conservation Biology 26(2): 367-371.

552 ICCAT. 2009. Report of the 2008 Atlantic Bluefin Tuna Stock Assessment Session. Collective

553 Volume of Scientific Papers ICCAT 64: 1-352

554 ICCAT. 2013. Report of the 2012 Atlantic Bluefin Tuna Stock Assessment Session. Collective

555 Volume of Scientific Papers ICCAT. In press.

556 Jacquet, J.L. And Pauly, D. 2008. Trade secrets: Renaming and mislabeling of seafood. Marine

557 Policy 32 (2008) 309-318.

558 Lowenstein JH, Amato G, Kolokotronis S-O. 2009. The Real maccoyii: Identifying Tuna Sushi

559 with DNA Barcodes - Contrasting Characteristic Attributes and Genetic Distances. PLoS ONE 
560

561

562

563

564

565

566

567

568

569

570

571

572

573

574 Miller DD, Jessel A, Mariani S. 2012. Seafood mislabelling: comparisons of two western

575 European case studies assist in defining influencing factors, mechanisms and motives. Fish and

576 fisheries 13: 345-358.

577 Miller DD, Mariani S. 2010. Smoke, mirrors, and mislabeled cod: poor transparency in the

578 European seafood industry. Frontiers in Ecology and the Environment 8(10): 517-521.

579 R Core Team. 2013. R: A language and environment for statistical computing. R Foundation for

580 Statistical Computing, Vienna, Austria. URL http://www.R-project.org/.

581 Rasmussen RS, Morrissey MT. 2008. DNA-Based methods for the identification of commercial

582 fish and seafood species. Compr. Rev. Food Sci. Food Safety 7, 280- 295.

583 Ratnasingham S, Hebert P. 2007. BOLD: The Barcode of Life Data System.

584 (www.barcoding.life.org) Mol Ecol Notes 7:355-364. Last accessed 03-03-2014

585 Regulation (EC) http://eur-lex.europa.eu/. Last accessed march 2014.

586 Vinas J, Tudela S. 2009. Validated methodology for genetic identification of tuna species (genus

587 Thunnus). PloSONE 4:e7606.

588 von der Heyden S, Barendse J, Seebregts AJ, Matthee CA. 2010. Misleading the masses:

589 detection of mislabeled and substituted frozen fish products in South Africa. ICES Journal of

590 Marine Science 67, 176-185. 
591 Ward RD, Hanner R, Hebert PD. 2009. The campaign to DNA barcode all fishes. FISH-BOL.

592 Journal of Fisheries Biology 74, 329-356.

593 Winnepenninckx B, Backeljau T, De Wachter R. 1993. Extraction of high molecular weight DNA

594 from molluscs. Trends in Genetics 9, 407.

595 Wong EH-K, Hanner RH. 2008. DNA barcoding detects market substitution in North American

596 seafood. Food Research International 41: 828-837

597 Yancy HF, Zemlak TS, Mason JA, Washington JD, Tenge BJ, Nguyen NT, Barnett JD, Savary

598 WE, Hill WE, Moore MM, Fry FS, Randolph SC, Rogers PL and Hebert PDN. 2008. The

599 Potential Use of DNA Barcodes in Regulatory Science: Applications of the Regulatory Fish

600 Encyclopedia. Journal of Food Protection 71(1):210-7. 


\section{1}

Substitution rates for different commercial name categories

Species categories with more than 10 samples collected have comparable, low substitution rates; substitutions were observed in only three of the categories. Bluefin tuna displays an exceptionally high substitution rate, and was separated from other tuna species in the figure and in analyses, despite a very low number of samples $(n=6)$. Error bars show the $95 \%$ confidence interval. The red dashed line is the average substitution rate observed for the entire dataset. 


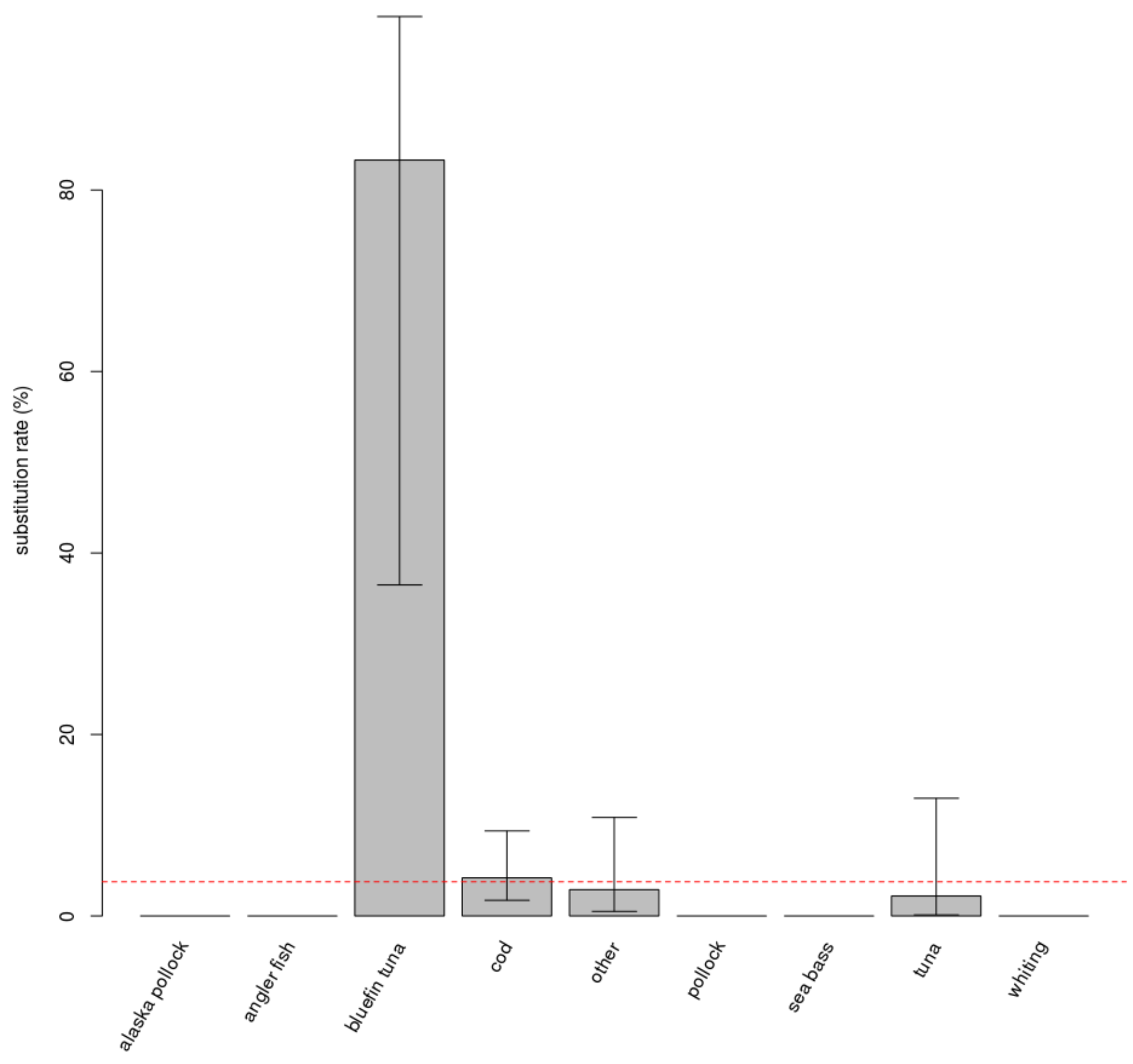




\section{Table 1 (on next page)}

Summary of the sampled species

The samples are presented per protocol (FL or TE) and commercial name. When several species are sold under one name, the species present in the dataset according to molecular ID are highlighted in bold. The number in brackets are the number of substitutions observed after sample sorting. Table assembled using http://www.economie.gouv.fr/dgccrf/Poissons.

* no qualifier is needed for restaurants for the commercial name to be correct. 


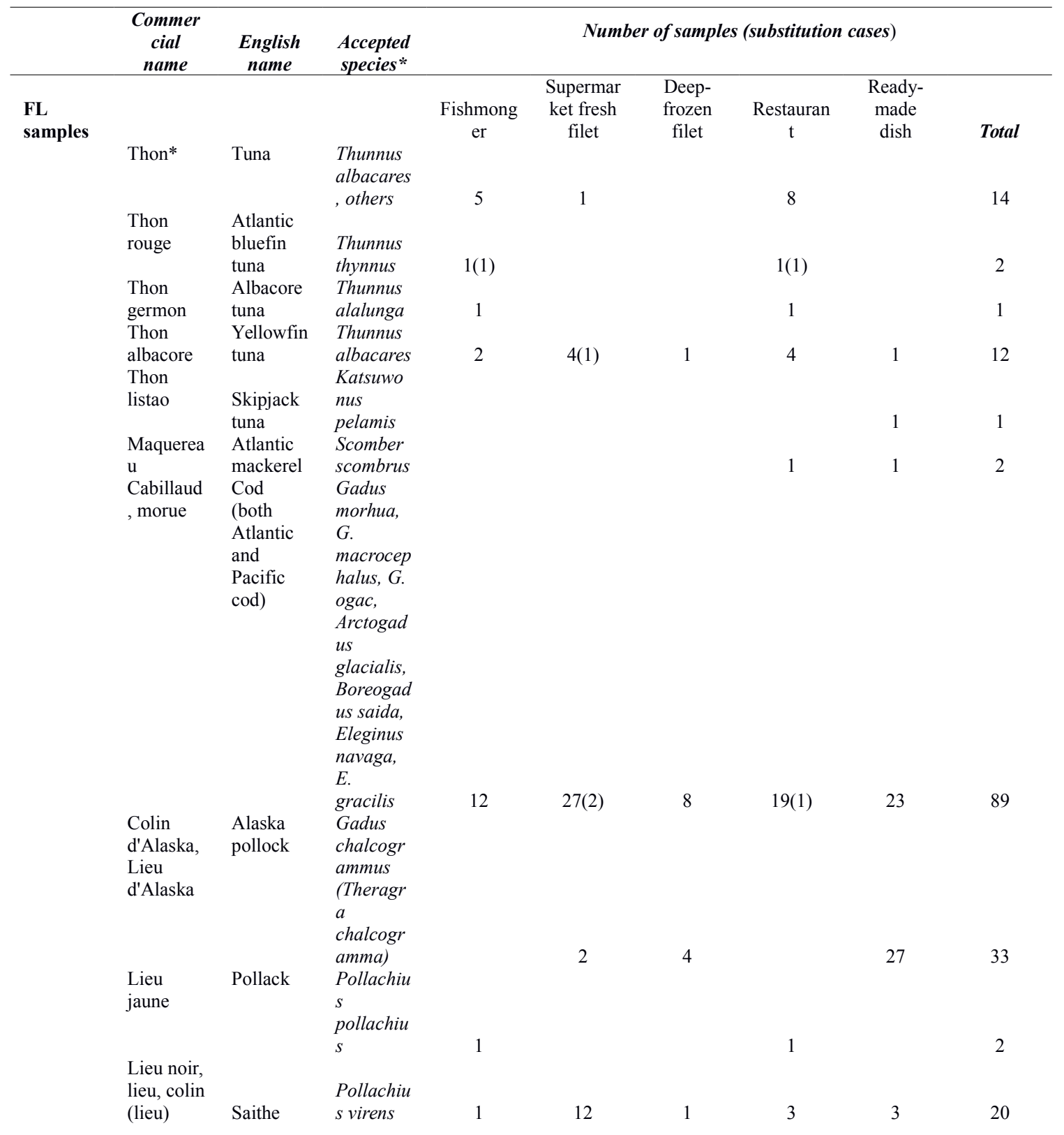




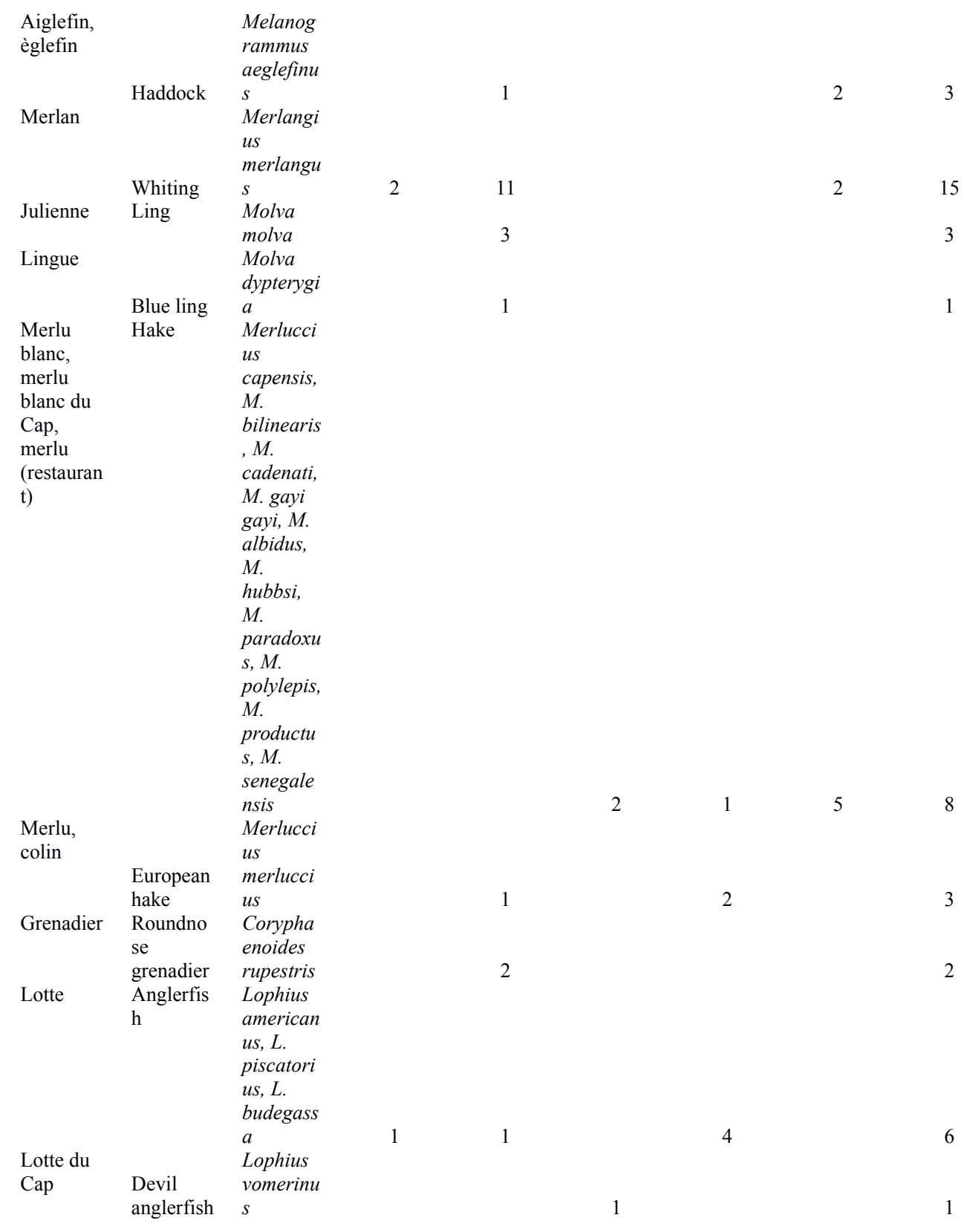




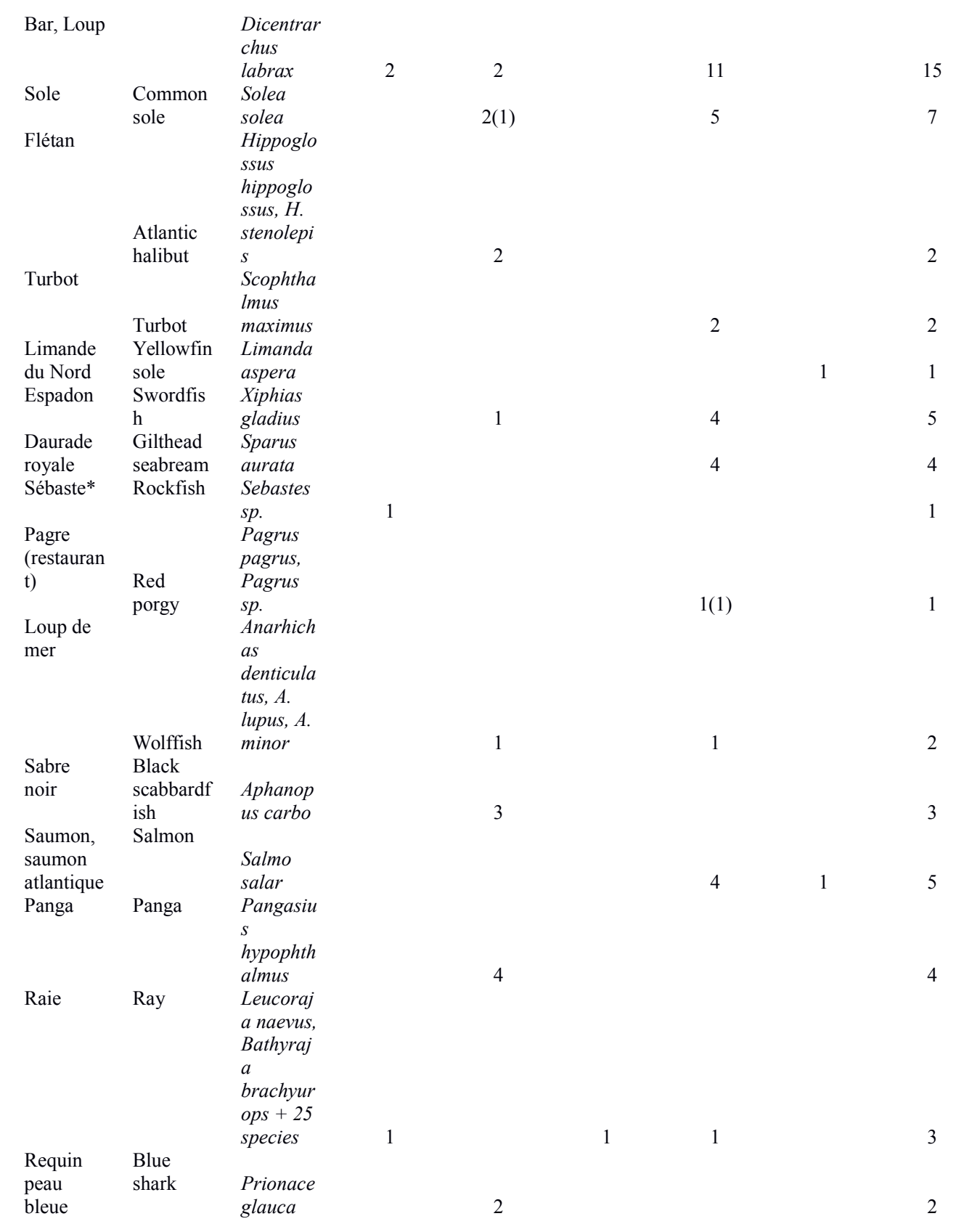


Rouget Mullus

surmule

us

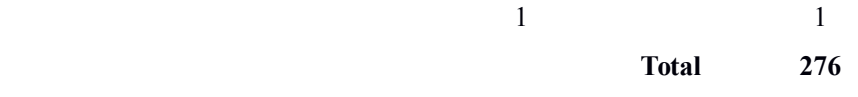

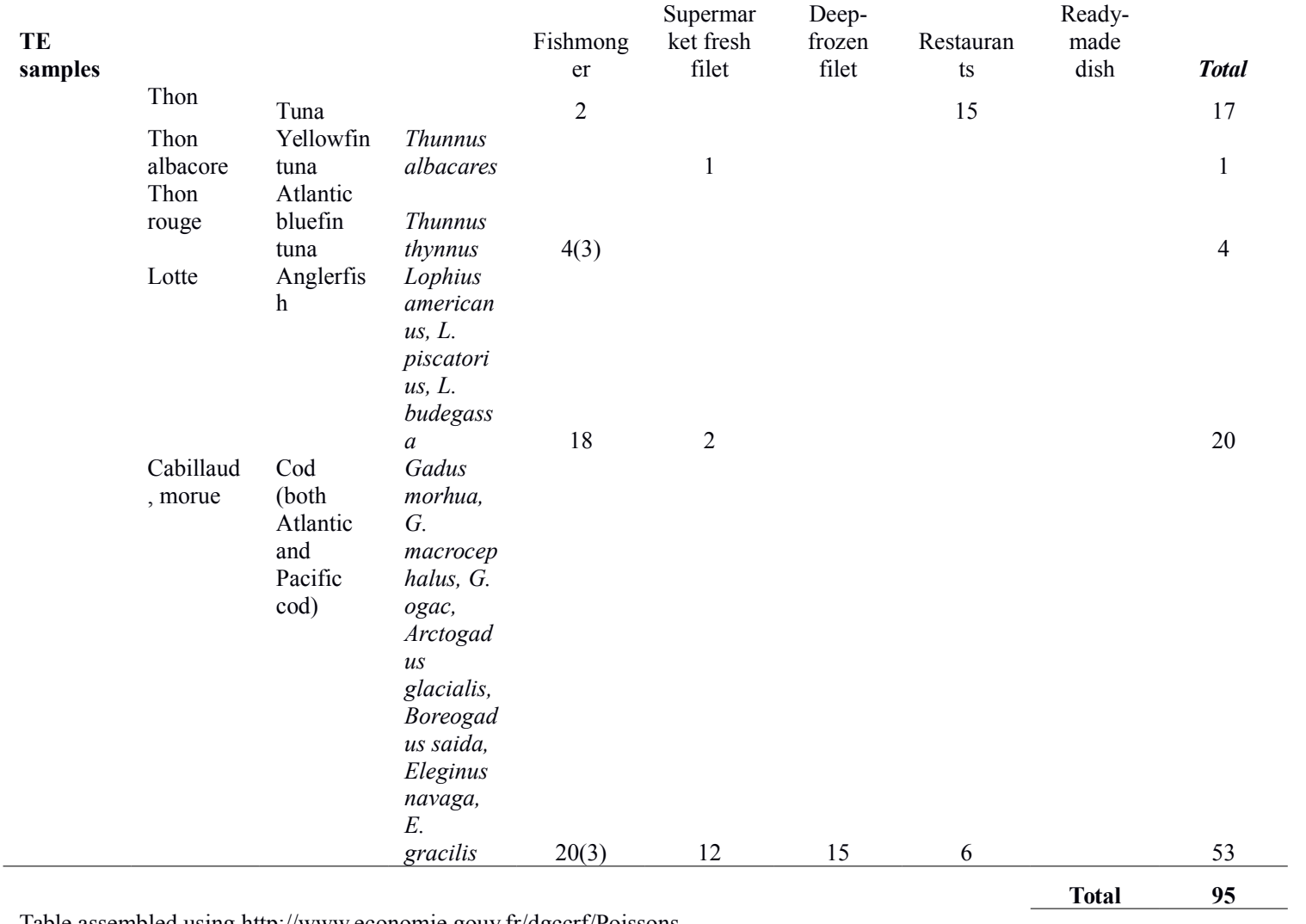

Table assembled using http://www.economie.gouv.fr/dgccrf/Poissons

*No qualifier is needed for restaurants the commercial denomination to be correct

Numbers in brackets are the number of substitutions after sample sorting 


\section{Table 2 (on next page)}

Substitution cases

The "thon rouge" (bluefin tuna) category account for 5 out of the 14

substitions observed in our sampling $(n=371)$, although it contains only 6 samples. 


\begin{tabular}{cccccccc}
\hline Sample & $\begin{array}{c}\text { Commercial name (latin } \\
\text { name if indicated) }\end{array}$ & $\begin{array}{c}\text { Dataset } \\
\text { length }\end{array}$ & $\begin{array}{c}\text { Similarity with BOLD } \\
\text { sequences }\end{array}$ & Molecular identification & Origin \\
\hline Tuna & & & & & & \\
Zipcode
\end{tabular}




\section{Table 3(on next page)}

Substitution rates observed in similar studies

These studies all used molecular identification to estimate the rate of species substitution. 


\begin{tabular}{|c|c|c|c|c|c|c|c|}
\hline $\begin{array}{l}\text { Investigated } \\
\text { country }\end{array}$ & $\begin{array}{c}\text { Substitution } \\
\text { rate }\end{array}$ & Nb of sequences & Taxonomic focus & Origin $^{1}$ & Type $^{2}$ & Marker & Reference \\
\hline \multicolumn{8}{|l|}{$\mathbf{E U}$} \\
\hline Ireland & $19.00 \%$ & 111 & diverse & $\mathrm{F}, \mathrm{S}, \mathrm{R}$ & $\mathrm{Fl}, \mathrm{Fr}, \mathrm{P}, \mathrm{Rd}$ & $\mathrm{COI}$ & FSAI 2011 \\
\hline Ireland & $25.00 \%$ & 156 & $\operatorname{cod}$ & F, S, F\&C & $\mathrm{Fl}, \mathrm{Fr}, \mathrm{Rd}$ & $\mathrm{COI}$ & Miller \& Mariani 2010 \\
\hline Ireland & $28.20 \%$ & 131 & $\operatorname{cod}$ & $\mathrm{F}, \mathrm{S}, \mathrm{F} \& \mathrm{C}$ & $\mathrm{Fl}, \mathrm{Fr}, \mathrm{P}, \mathrm{Rd}$ & $\mathrm{COI}$ & Miller et al. 2012 \\
\hline Ireland/UK & na & 98 & Rajidae & F, S, F\&C & $\mathrm{Fl}, \mathrm{Rd}$ & $\mathrm{COI}$ & Griffith et al. 2013 \\
\hline UK & $7.40 \%$ & 95 & $\operatorname{cod}$ & F, S, F\&C & $\mathrm{Fl}, \mathrm{Fr}, \mathrm{P}, \mathrm{Rd}$ & COI & Miller et al. 2012 \\
\hline UK & $<1.5 \%$ & 142 & diverse & $\mathrm{S}$ & $P$ & $\mathrm{COI}$ & Huxley-Jones et al. 2011 \\
\hline Italy & $32.00 \%$ & 69 & diverse & $\mathrm{F}, \mathrm{S}$ & $\mathrm{Fl}, \mathrm{Fr}$ & COI \& Cytochrome b & Filonzi et al. 2010 \\
\hline Italy & $77.80 \%$ & 59 & Mustelus sp. & $\mathrm{F}, \mathrm{S}$ & $\mathrm{Fl}$ & $\mathrm{COI}$ & Barbuto et al. 2009 \\
\hline Italy & $56.36 \%$ & 110 & $\operatorname{cod}$ & $\begin{array}{c}\text { S } \\
\text { Port }\end{array}$ & $\mathrm{Fl}, \mathrm{P}$ & $\mathrm{COI}$ & Di Pinto et al. 2013 \\
\hline Italy & $20.00 \%$ & 18 & diverse & authorithy & $\mathrm{P}$ & COI \& Cytochrome b & Curatelli et al. 2014 \\
\hline Spain & $>20 \%$ & 40 & Hake & S & $\mathrm{Fr}, \mathrm{P}$ & Mt Control region SNPs & Machado-Schiaffino et al. 2008 \\
\hline Spain \& Greece & $>30 \%$ & $279(93 * 3)$ & Hake & $\mathrm{S}$ & $\mathrm{Fr}$ & 5S rDNA, CytB RFLP & Garcia-Vasquez et al. 2011 \\
\hline France & $3.7 \%$ (ci 2.2-6.4) & 371 & diverse & $\mathrm{F}, \mathrm{S}, \mathrm{R}$ & $\mathrm{Fl}, \mathrm{Fr}, \mathrm{P}, \mathrm{Rd}$ & $\mathrm{COI}$ & present study \\
\hline $\begin{array}{c}\text { Non-EU } \\
\text { Japan }\end{array}$ & $8.00 \%$ & 26 & Tuna & $\mathrm{F}, \mathrm{R}$ & $\mathrm{Fl}, \mathrm{Rd}$ & $\begin{array}{l}\text { COI, Mt Control region, } \\
\text { ITS } 1\end{array}$ & Vinas \& Tudela 2009 \\
\hline South Africa & $21.00 \%$ & 248 & diverse & $\mathrm{S}, \mathrm{F}$ & $\mathrm{Fl}, \mathrm{Fr}, \mathrm{P}$ & $\mathrm{COI}$ & Cawthorne et al. 2012 \\
\hline South Africa & $50.00 \%$ & 174 & diverse & $\mathrm{R}, \mathrm{F}$ & $\mathrm{Fl}, \mathrm{Fr}$ & 16S rDNA & von der Heyden et al. 2010 \\
\hline Canada & $41.20 \%$ & 236 & diverse & $\mathrm{F}, \mathrm{S}, \mathrm{R}$ & $\mathrm{Fl}, \mathrm{Fr}, \mathrm{Rd}$ & $\mathrm{COI}$ & Hanner et al. 2011 \\
\hline US & $32,35 \%$ & 68 & Tuna & $\mathrm{R}$ & $\mathrm{Rd}$ & COI & Lowenstein et al. 2009 \\
\hline US & $11.00 \%$ & 99 & Salmon & $\mathrm{R}, \mathrm{S}$ & $\mathrm{Fl}$ & $\mathrm{COI}$ & Cline 2012 \\
\hline US \& Canada & $25.00 \%$ & 90 & diverse & $\mathrm{F}, \mathrm{R}$ & $\mathrm{Fl}, \mathrm{Rd}$ & $\mathrm{COI}$ & Wong \& Hanner 2008 \\
\hline
\end{tabular}

${ }^{1} \mathrm{~F}=$ Fishmongers, $\mathrm{S}=$ supermarkets, $\mathrm{F} \& \mathrm{C}=\mathrm{Fish}$ and chips, $\mathrm{R}=$ restaurants

${ }^{2} \mathrm{Fr}=$ frozen, $\mathrm{P}=$ prepared dish (includes fishfingers and battered), $\mathrm{Fl}=$ Fillet, Rd=Restaurant dish 